\title{
Characterization of Rhizobium Isolates and their Potential PGPR Characteristics of different Rhizosphere Soils of Telangana Region, India
}

\author{
K. Manasa*, R. Subhash Reddy, S. Triveni, B. Kranthi Kumar and N. Gowri Priya
}

Department of Agricultural Microbiology and Bioenergy, College of Agriculture, Professor Jayashankar Telangana State Agricultural University, Rajendranagar, Hyderabad-500030, India *Corresponding author:

\section{A B S T R A C T}

\begin{tabular}{|l|}
\hline Ke y w or d s \\
Rhizobium, PGPR, \\
Rhizospheric, \\
Heavy metals \\
\hline Article Info \\
\hline $\begin{array}{l}\text { Accepted: } \\
\text { 26 April } 2017 \\
\text { Available Online: } \\
\text { 10 May 2017 }\end{array}$ \\
\hline
\end{tabular}

PGPR function in three different ways synthesizing particular compounds for the plants facilitating the uptake of certain nutrients from the soil and lessening or preventing the plants from diseases. Some of Plant growth promoting characteristics such as phosphate solubilisation, Indole acetic acid (IAA) capacity, ability to produce ammonia $\left(\mathrm{NH}_{3}\right)$ as sole nitrogen source, siderophore production and production of hydrogen cyanide were evaluated in fifteen Rhizobacteria isolated from different rhizosphere soils of groundnut, sunflower, maize, black gram, green gram, rice, soy bean and redgram. In this study, $47 \%$ Rhizobial isolates showed phosphate solubilization.73\% of the isolates showed IAA production and $100 \%$ for ammonia, 53\% for siderophores and 53\% isolates showed for $\mathrm{HCN}$ production. All the fifteen isolates were examined for the potential to inhibit two fungal pathogens viz., Rhizoctonia solani and Sclerotium rolfsii under in vitro conditions. Out of fifteen isolates, only 3 isolates exhibited inhibition potential against two soil borne plant phytopathogen Among these isolates, RR-1 and GNR-1 were tolerant to all the heavy metals $\left(100 \mu \mathrm{g} \mathrm{ml}^{-1}\right)$.

\section{Introduction}

Several environmental factors adversely affect the plant growth and development and final yield performance of a crop. Drought, salinity, nutrient imbalances and extremes of temperature are among the major environmental constraints to crop productivity worldwide. Soil pollution, is a very important environmental problem and it has been attracting considerable attention in recent years (Garbisu, 2001; Marques, 2009). Human activities, such as mining operations and the discharge of industrial wastes, have resulted in the accumulation of metals in the environment. It has been reported that microorganisms become adapted to these environments by the acquisition of specific resistance systems (Yilmaz, 2003). Rhizobacteria have been classified into beneficial, deleterious and neutral according to their effect on host (Benizri, 2001). Development of crop plants with stress tolerance is a very important research. Recently, the scientists try to improve plant tolerance to extreme environmental conditions through the biofertilizers treatments (symbiotic nitrogen fixing bacteria, asymbiotic nitrogen fixing bacteria and mycorrhiza). Rhizobium population tolerate to major environmental factors than their host legumes. Rhizobium symbiosis with 
leguminous plants and fix atmospheric $\mathrm{N}_{2}$. Rhizobium spp. are gram-negative soil bacteria that have a profound scientific and agronomic significance due to their ability to establish nitrogen-fixing symbiosis with leguminous plants, which is of major importance to the maintenance of soil fertility (Somasegaran, 1994). For this reason and taking into consideration the importance of legumes in animal and human consumption, some attention has been given to the effects that heavy metals exert on Rhizobium isolates as free-living organisms or symbiotically associated with legumes (Ibekwe, 2010).

\section{Materials and Methods}

\section{Collection of Sample}

Eight different rhizospheric soil samples were collected from Groundnut, Sunflower, Maize, Black gram, Green gram, Rice, Soy bean and Redgramfield grown in PJTSAU Rajendranagar, Hyderabad. The sample was collected in $1 \mathrm{~cm}$ depth and it was packed in a sterile polythene bag and labelled properly.

\section{Isolation of Rhizobium Isolates}

The isolation of Rhizobium spp. from soil samples, $1 \mathrm{~g}$ of soil sample was serially diluted in sterile distilled water, $0.1 \mathrm{ml}$ of soil suspension from 10-1 to 10-6 was spreaded on yeast extract mannitol agar (Collavino, 2010).

\section{Identification of Rhizobium spp}

The bacterial isolates were identified by using cultural, morphological and biochemical characteristics features described in Bergey's manual of determinative bacteriology and stored at $4^{\circ} \mathrm{C}$ on slants and maintained through sub-culturing. The isolates were characterized by Gram staining, motility test, Methyl Red, Voges Proskauer, Citrate, oxidase test, catalase test, $\mathrm{H} 2 \mathrm{~S}$ production and starch hydrolysis as per the standard methods.

In vitro screening of multiple plant growth promoting activities of Rhizobium spp.

\section{Production of indole acetic acid}

Bacterial cultures were grown for Rhizobium on their respective media at $36 \pm 2{ }^{\circ} \mathrm{C}$. Fully grown cultures were centrifuged at $3000 \mathrm{rpm}$ for $30 \mathrm{~min}$. The supernatant $(2 \mathrm{ml})$ was mixed with two drops of orthophosphoric acid and 4 $\mathrm{ml}$ of the Salkowski reagent $(50 \mathrm{ml}, 35 \%$ of perchloric acid, $1 \mathrm{ml} 0.5 \mathrm{M} \mathrm{FeCl} 3$ solution). Development of pink colour indicates IAA production.

\section{Production of HCN}

All the isolates were screened for the production of hydrogen cyanide by adapting the method briefly, nutrient broth was amended with $4.4 \mathrm{~g}$ glycine/l and bacteria were streaked on modified agar plate. A Whatman filter paper no. 1 soaked in $2 \%$ sodium carbonate in $0.5 \%$ picric acid solution was placed at the top of the plate. Plates were sealed with parafilm and incubated at $36 \pm 2{ }^{\circ} \mathrm{C}$ for 4 days. Development of orange to red colour indicated $\mathrm{HCN}$ production. Bacterial cultures were grown in a nutrient agar medium for $18-24 \mathrm{~h}$ at $36 \pm 2{ }^{\circ} \mathrm{C}$. The cultures were mixed with appropriate amount of $\mathrm{H}_{2} \mathrm{O}_{2}$ on a glass slide to observe the evolution of oxygen

\section{Ammonia production}

The isolates were tested for ammonia production by inoculating the isolates in to 10 $\mathrm{ml}$ of pre-sterilized peptone water in the test tubes. The tubes were incubated for $48-72 \mathrm{~h}$ at $36 \pm 2^{\circ} \mathrm{C}$. Nessler's reagent $(0.5 \mathrm{ml})$ was added in each tube. Change in colour of the 
medium from brown to yellow colour was taken as positive test for ammonia production.

\section{Phosphate solubilization}

Bacterial isolates were evaluated from the ability to solubilize inorganic phosphate. Pikovskaya's agar medium (HiMedia, Mumbai) containing calcium phosphate as the inorganic form of phosphate was used in this assay. A loopful of bacterial culture were placed on the plates and kept for incubation at $28^{\circ} \mathrm{C}$ for 7 days. The presence of clear zone around the isolate indicate positive for the test.

\section{Siderophore production}

Siderophore production was estimated qualitatively. Chrome Azurol S (CAS) Agar medium (Schwyn and Neilands, 1987): For the detection of siderophores, each Pseudomonas isolate was grown in synthetic medium, containing $0.5 \mu \mathrm{M}$ of iron and incubated for $24 \mathrm{~h}$ on a rotary shaker at room temperature. Chrome Azurol S (CAS) assay is used to detect the siderophores. The CAS plates were used to check the culture supernatant for the presence of siderophores. Culture supernatant was added to the wells made on the CAS agar plates and incubated at room temperature for $24 \mathrm{~h}$. Formation of yellow to orange coloured zone around the well indicates siderophore production.

\section{Antagonistic activity}

Pure isolates of common disease causing soil phytopathogens viz, Rhizoctonia solani, Sclerotium rolfsii were obtained from the Dept. of Plant Pathology, College of Agriculture, Rajendranagar. Antagonistic activity was verified by following dual culture technique (Skidmore and Dickinson, 1976). First, the bacterial isolates were streaked on respective media plates and incubated at respective temperature and time. Loop ful of each bacterial isolate was streaked on the potato dextrose agar plate at one end, which was pre-inoculated with 5 days old, $5 \mathrm{~mm}$ mycelial disc of test pathogen at the other end. Control plate was maintained by placing only pathogen mycelial disc in the centre without bacteria.

The assay plates were incubated at $28 \pm 1^{0} \mathrm{C}$ for 5 days and observations were made on inhibition of mycelial growth of the test pathogens. For each bacterial isolate three replications were maintained with suitable controls.

\section{Results and Discussion}

\section{Screening of pure isolates for PGPR properties}

Plant root colonizing bacteria can function as harmful, deleterious rhizobacteria (DRB) or beneficial, plant growth promoting rhizobacteria (PGPR). PGPR colonize roots of monocots and dicots, and enhance plant growth by direct and indirect mechanisms. Modification of root system architecture by PGPR implicates the production of phytohormones and other signals that lead, mostly to enhanced lateral root branching and development of root hairs. PGPR also modify root functioning, improve plant nutrition and influence the physiology of the whole plant.

For identification of efficient PGPR strains with multiple activities, microbial isolates (Rhizobium and Pseudomonas fluorescence) were subjected to further studies to understand their Plant Growth Promoting Properties (PGPR) under in vitro conditions.

\section{IAA production}

Out of fifteen Rhizobial isolates 11 were able to produce IAA. Further, out of 15 isolates 


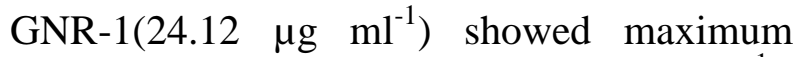
IAA, followed by SFR-1(15.20 $\left.\mu \mathrm{g} \mathrm{ml} \mathrm{m}^{-1}\right)$, GGR-2(14.24 $\left.\mathrm{g} \mathrm{ml}^{-1}\right)$, MR-1 (13.24 $\left.\mu \mathrm{g} \mathrm{ml}^{-1}\right)$, GGR-1(12.24 $\left.\mathrm{g} \mathrm{ml}^{-1}\right)$, RGR-1 (12.22 $\mu \mathrm{g} \mathrm{ml}^{-}$ $\left.{ }^{1}\right), \operatorname{RR}-1\left(12.14 \mu \mathrm{g} \mathrm{ml}^{-1}\right)$, GNR-2 $\left(11.41 \mu \mathrm{g} \mathrm{ml}^{-}\right.$ $\left.{ }^{1}\right), \operatorname{SFR}-2\left(11.34 \mu \mathrm{g} \mathrm{ml}^{-1}\right), \mathrm{MR}-2\left(11.25 \mu \mathrm{g} \mathrm{ml}^{-}\right.$ $\left.{ }^{1}\right), \operatorname{RR}-2\left(9.14 \mu \mathrm{g} \mathrm{ml}^{-1}\right)$

Collavino (2010) reported that phosphatesolubilizing bacteria native to acid soilhad ability to promote Phaseolus vulgaris growth. The study is conducted to characterize three bacterial strains in solubilising rock phosphates as well as their impact in promoting soybean growth under pot grown conditions

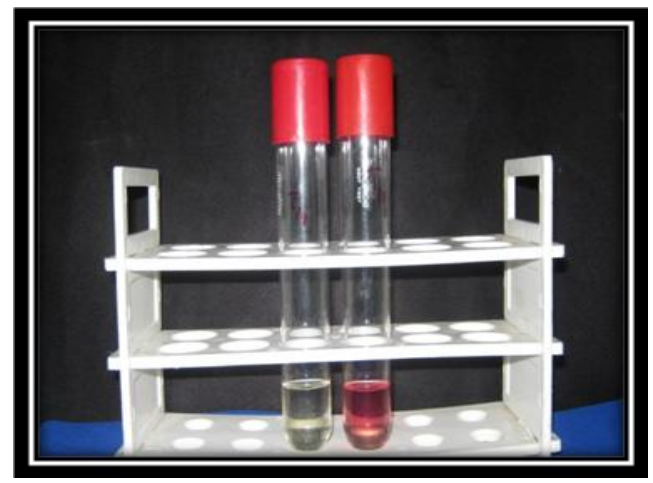

HCN Production

Out of 15 Rhizobium isolates, 8 produced HCN. Further, out of 8 isolates RR-1 exhibited strong (+++) $\mathrm{HCN}$ production and GNR-1 scored as moderate (++) for $\mathrm{HCN}$ production. Whereas the remaining 6 isolates viz, MR-2, BGR-1, GNR-2, GGR-2, SFR-2, SYR-1 foundto be weak (+)in $\mathrm{HCN}$ production

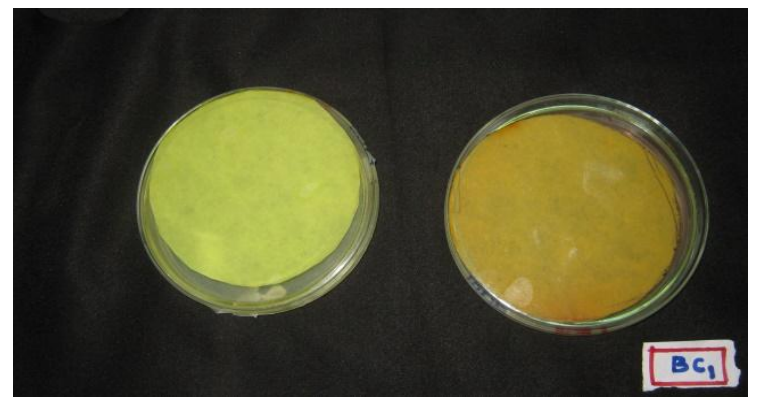

Ammonia production
Out of 15 Rhizobium isolates 15 were able to produce ammonia. Further, out of 15 isolates RR-1 exhibited strong (+++) Ammonia production and MR-1,MR-2,MR-3,BGR1,GNR-1,GNR-2,GGR-1,SFR-1,SFR-2, RGR1 and SYR-1 produced moderately (++). Whereas the remaining 3 isolates viz, RR-2, BGR-1, MR-4 and GGR-2 were scored as weak (+) for Ammonia production

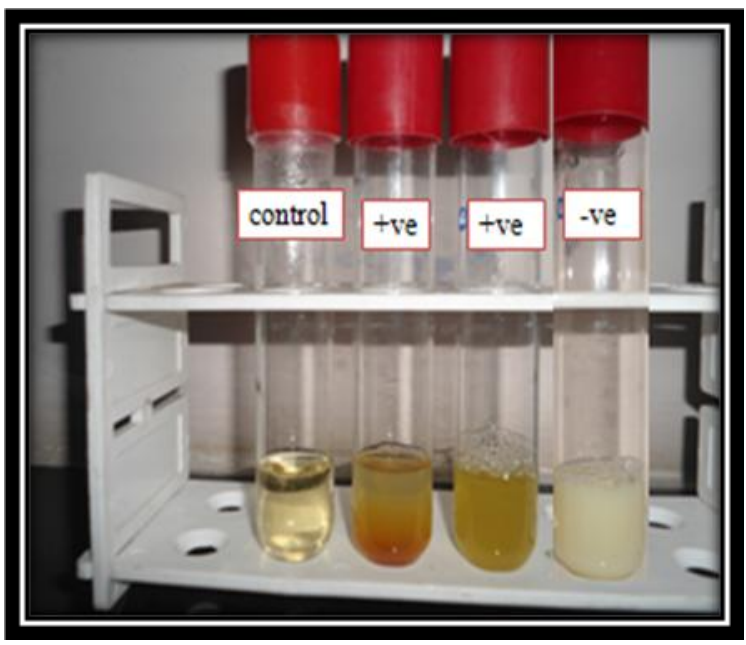

Phosphate solubilization

Among 15 Rhizobial isolates 7 isolates were able to solubilize phosphate on pikovskaya's media containing Tri calcium phosphate in the range of $10 \mathrm{~mm}$ to $25 \mathrm{~mm}$. Among 7 Rhizobial isolates SFR-2 recorded the highest solubilization zone $(22.00 \mathrm{~mm})$ (Plate.4.3(a)) followed by RR-1 \& MR-1 (19 mm), GNR-2 $(18.00 \mathrm{~mm}), \quad \mathrm{RR}-2(14.00 \mathrm{~mm})$ and less solubilization by GNR-1,SYR-1(10.00mm).

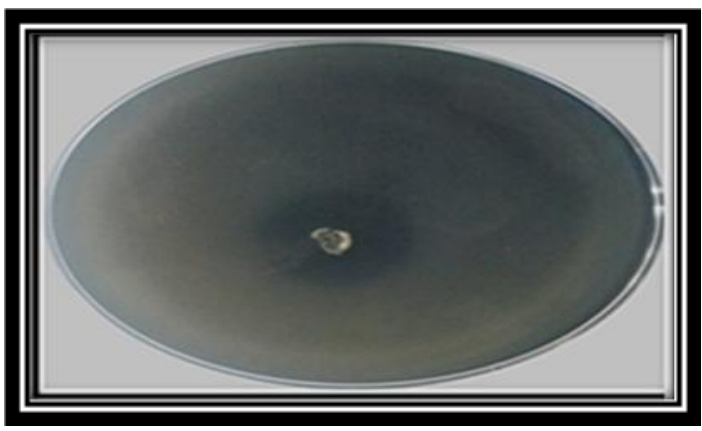

Siderophore production 
Out of 15 Rhizobium isolates 8 were able to produce siderophores. Further, out of 8 isolates RR-1 exhibited strong (+++) Siderophore production and GNR-1 and SYR1 produced moderately $(++)$. Whereas the remaining 5 isolates viz, RR-2, BGR-1,GNR2,GGR-1 and SFR-2 were scored as weak (+) for Siderophore production.

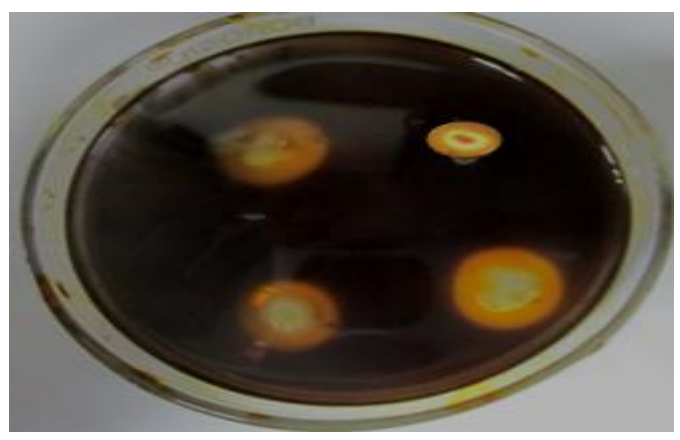

Arora et al, (2001) stated that siderophore producton by Rhizobial strains has been considered as a potential way to improve nodulation and $\mathrm{N}_{2}$ fixation in iron deficiency conditions. The beneficial effect of using siderophore producing strains of Bradyrhizobium sp. and Rhizobium melilotimight favour the persistence of Rhizobia in iron deficient soils.

\section{Antagonistic activity of Rhizobium isolates}

Out of 15 Rhizobium isolates 4 isolates showed inhibition potential against Rhizoctonia solani, viz. RR-1 (36.60\%), GNR-1 (36.05\%), SFR-2 (36.60\%) and SYR-1 $(36.60 \%)$. The maximum per cent inhibition against Rhizoctonia solani was showed by SYR-1 (36.66\%) with inhibition zone $4 \mathrm{~mm}$

Four out of 15 isolates were inhibitory to Sclerotium rolfsii, viz. RR-1 (36. 05\%), GNR1 (37.50\%), GNR-2 (36.60\%) and SFR-2 (31.10\%)The maximum per cent inhibition against Sclerotium rolfsii, was showed by GNR -1 (37.50\%) with inhibition zone $3 \mathrm{~mm}$

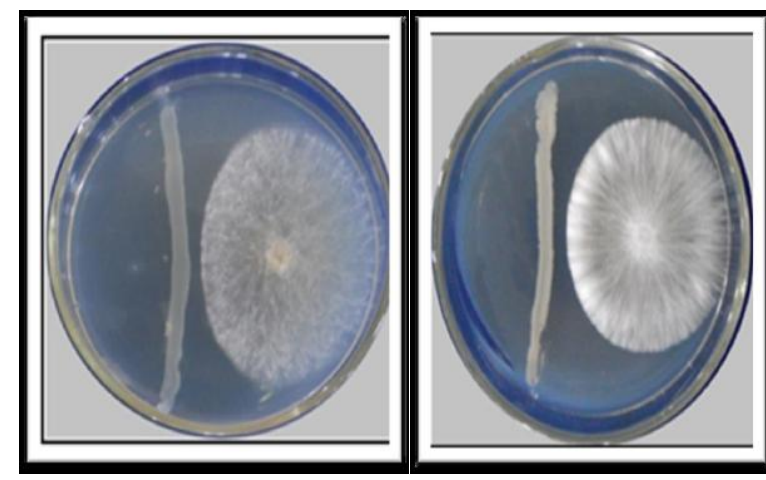

Rhizobium with Rhizoctonia solani, Rhizobium with Sclerotium rolfsii

Out of 15 Rhizobium isolates 3 isolates viz, RR-1, GNR-1and SFR-2 showed inhibition potential against both Rhizoctonia solani and Sclerotium rolfsii, the isolate that showed maximum inhibition potential against Rhizoctoniasolani was also inhibitory to Sclerotium rolfsii to a lesser extent based on per cent inhibition and vice versa. Hence it can be inferred that the Rhizobium isolates RR-1, GNR-1and SFR-2 could be considered for their bio control activity.

\section{References}

E. Benizri, E. Baudoin, A. Guckert, Root colonization by inoculated plantgrowthpromoting rhizobacteria. Biocon. Sci. Tech. 11 (2001) 557-574.

Collavino, M.M P.A. Sansberro, L.A. Mroginski, O.M. Aguilar 2010. Comparison of in vitro solubilization activity of diverse phosphatesolubilizing bacteria native to acid soiland their ability to promote Phaseolus vulgaris growth. Biology Fertility of Soils. 46:727-738.

Garbisu, C., Alkorta, I Phytoextraction: a cost effective plant based technology for the removal of metals from the environments. Biores. Technol.77 (2001) 229-236.

A.M. Ibekwe, J.S. Angle, R. L. Chaney, P. Van berkum, Sewage sludge and heavy 
metal effects on nodulation and nitrogen fixation of legumes. J. Environ. Qual. 24 (1995)1199- 1204.

Marques, A. P. G. C.,H. Moreira, A. O. S. S. Rangel, P. M. L. Castro, Arsenic, lead and nickel accumulation in Rubus ulmifolius growing in contaminated soil in Portugal. Journal of Hazardous Materials. 165 ( 2009) 174-179.

Skidmore, A.M and Dickinson, C.H. 1976. Colony interaction and hyphal interference between Septorianodorum and phylloplane fungi. Transactions and Journal of the British Ceramic Society. 66: $57-74$

Collavino, M.M P.A. Sansberro, L.A. Mroginski, O.M. Aguilar 2010.
Comparison of in vitro solubilization activity of diverse phosphatesolubilizing bacteria native to acid soiland their ability to promote Phaseolus vulgaris growth. Biology Fertility of Soils. 46:727-738.

Schwyn, B. and Neilands, J.B. 1987. Universal chemical assay for the detection and determination of siderophores. Analytical Biochemistry.160: 47-56.

P. Somasegaran, H.J. Hoben, Handbook for Rhizobia, Springer-Vera, Berlin, 1994.

E.I. Yilmaz, Metal Tolerance and Biosorption Capacity of Bacillus circulans Strain EB1. Research in Microbiology. 154 (2003) 409-415.

\section{How to cite this article:}

Manasa, K., R. Subhash Reddy, S. Triveni, B. Kranthi Kumar and Gowri Priya, N. 2017. Characterization of Rhizobium Isolates and their Potential PGPR Characteristics of different Rhizosphere Soils of Telangana Region. Int.J.Curr.Microbiol.App.Sci. 6(5): 2808-2813. doi: https://doi.org/10.20546/ijcmas.2017.605.316 